\title{
The Influence Of Communication And Work Environment To Employee Performance At the Central Bureau of Statistics (BPS) of Solok Regency
}

\author{
Aldi Fitra, Henryanto Abaharis \\ STIE "KBP” \\ mikhialdi@yahoo.com
}

\begin{abstract}
Attention to human resources in a company or organization is very important to obtain employee performance as expected by the company. Employee performance is influenced by many factors including organizational communication, and work environment. This study aims to analyze the influence of organizational communication and work environment on employee performance at the Central Bureau of Statistics (BPS) Solok District. Organizational communication is the breath of an organization's sustainability. An organization will not work without communication. The work environment is something that is around the workers and that affects itself in carrying out the tasks charged. The population of this study is all employees of the Central Bureau of Statistics (BPS) in Solok District this sampling technique using simple random sampling technique, with a sample of 26 people. Data collection is done by kusioner method. The data obtained were analyzed multiple regression to test the effect of organizational communication and work environment on employee performance. The result showed $Y=17,722+0,168 X 1+0,385 X 2$ Then it can be said there is significant influence between organizational communication variable and work environment with employee performance. From the results of significant significant research $0.000<0.1 \%$ which affects the dependent variable.
\end{abstract}

Keywords: organizational communication, work environment, performance

\section{PENDAHULUAN}

Sumber daya manusia
merupakan faktor terpenting dalam
perkembangan perusahaan swasta
dan pemerintahan. Sumber daya
manusia dalam perusahaan adalah
semua orang yang terlibat dalam
pengembangan perusahaan khususnya
karyawan. Sebuah perusahaan
membutuhkan seorang karyawan
yang kompeten dan kreatif guna
mencapai tujuan perusahaan.
komunikasi adalah bentuk interaksi
manusia yang saling pengaruh
mempengaruhi satu sama lainnya,
sengaja atau tidak sengaja.
Salah satu faktor yang
mempengaruhi tingkat keberhasilan
suatu organisasi adalah kinerja
karyawannya. Setiap perusahaan
mengharapkan karyawannya

mempunyai prestasi, karena karyawan berprestasi memberikan keuntungan bagi suatu perusahaan.

Untuk meningkatkan kinerja karyawan, diantaranya adalah dengan memperhatikan komunikasi organisasi anatara karyawannya. Karena dengan komunikasi yang tidak efektif suatu, perusahaan tidak akan bisa mencapai visi dan misi perusahaan.

salah satu kekuatan yang paling menghambat suksesnya kinerja kelompok adalah kurangnya komunikasi yang efektif. Pada era saat ini, sudah banyak yang melupakan pentingnya komunikasi dalam organisasi karena banyak yang lebih mementingkan menyelesaikan tanggung jawab pekerjannya, dibandingkan berkomunikasi dengan 
pihak-pihak yang ada di dalam organisasi.

Selain kominikasi organisasi, faktor yang mepengaruhi kinerja karyawan adalah lingkungan kerja, lingkungan kerja fisik dalam suatu perusahaan merupakan suatu kondisi pekerjaan untuk memberikan suasana yang nyaman dalam pencapai keinginan suatu perusahaan. Lingkungan kerja yang buruk menyebabkan karyawan malas berkumunikasi sesama karyawan, malas melakukan kewajiban sebagai karyawan, dan menurunnya produktivitas kerja.

Dalam mencapai

kenyamanan tempat bekerja antara lain dapat dilakukan dengan jalan memilihara prasarana fisik seperti kebersihan, pencahayaan, vantilasi udara, suara musik dan tataruang kantor yang nyaman. Kondisi seperti inilah yang harus diciptakan perusahaan untuk mencapai tujuan perusahaan, dan untuk meningkatkan kinerja karyawan.

Penelitian ini mengambil objek penelitian pada Badan Pusat Statistik (BPS) Kabupatan Solok yang merupakan Lembaga Pemerintah Non Departemen di Indonesia yang mempunyai fungsi pokok sebagai penyedia data statistik dasar, baik untuk pemerintah maupun untuk masyarakat umum, secara nasional maupun regional.

Badan Pusat Statistik (BPS) saat membutuhkan kinerja karyawan yang tinggi untuk meningkatkan produktivitas lembaga pemerintah. Oleh karena itu salah satunya adalah dengan meminimalisir komunikasi organisasi dan menciptakan lingkungan kerja yang baik serta kondusif.

Oleh karena itu, berdasarkan pernyataan-pernyataan di atas, maka penulis tertarik untuk mengadakan penelitian dengan judul “
PENGARUH

ORGANISASI

LINGKUNGAN

TERHAADAP

KARYAWAN PADA

PUSAT STATISTIK

KABUPATEN SOLOK"

\section{KAJIAN TEORI}

\section{KOMUNIKASI ORGANISASI}

Komunikasi adalah interaksi antara dua orang atau lebih. Di dalam komunikasi terdapat elemen komunikator sebagai penyampai pesan, media dan komunikan sebagai pihak yang bertugas menerima pesan. Pada dasarnya, elemen tersebut dapat berubah posisi sesuai kepentingan sebuah komunikasi yang terjadi. Bisa jadi komunikator beralih menjadi komunikan, begitu pula sebaliknya. Sedangkan maksud dari organisasi adalah sebuah wadah berkumpulnya orang-orang yang mempunyai tujuan bersama. Garis besar dari organisasi sendiri lebih mengarah kepada satu iktikad untuk mencapai tujuan bersama.

Menurut (Ruslan, 2006) bahwa komunikasi merupakan alat yang penting dalam fungsi public relation menaungi dan menghargai suatu kinerja yang baik tersebut untuk menarik perhatian publik serta tujuan penting yang lainya.

Menurut (Suprapto, 2011) komunikasi adalah suatu proses interaksi yang mempunyai arti antara sesama manusia. Berdasarkan kutipan-kutipan diatas, komunikasi dapat disimpulkan merupakan kegiatan interaksi yang dilakukan dari satu orang ke orang lain, sehingga akan tercipta persamaan makna dan tercapai satu tujuan.

\section{LINGKUNGAN KERJA}


Lingkungan kerja dalam suatu perusahaan sangat penting untuk diperhatikan manajemen. Meskipun lingkungan kerja tidak melaksanakan proses produksi dalam suatu perusahaan, namun lingkungan kerja mempunyai pengaruh langsung terhadap para karyawan yang melaksanakan proses produksi tersebut. Lingkungan kerja yang memusatkan bagi karyawannya dapat meningkatkan kinerja. Sebaliknya lingkungan kerja yang tidak memadai akan dapat menurunkan kinerja. Pada saat ini lingkungan kerja dapat didesain sedemikian rupa untuk menciptakan hubungan kerja yang mengikat pekerja dalam lingkungannya. Lingkungan kerja yang baik adalah yang aman, tenteram, bersih, tidak bising, terang dan bebas dari segala macam ancaman dan gangguan yang dapat menghambat karyawan untuk bekerja secara optimal.

Beberapa ahli mendefinisikan lingkungan kerja, antara lain sebagai berikut:

Menurut (Jay, 2001) lingkungan kerja merupakan lingkungan fisik tempat karyawan bekerja yang mempengaruhi kinerja, keamanan dan mutu kehidupan kerja mereka. Lingkungan kerja yang kondusif memberikan rasa aman dan memungkinkan para pegawai untuk dapat bekerja optimal. Lingkungan kerja dapat mempengaruhi emosi pegawai, jika pegawai menyenangi lingkungan kerja dimana ia bekerja, maka pegawai tersebut akan betah di tempat bekerjanya untuk melakukan aktivitas sehingga waktu kerja dipergunakan secara efektif dan optimal prestasi kerja pegawai juga tinggi. Lingkungan kerja tersebut mencakup hubungan kerja yang terbentuk antara sesama pegawai dan hubungan kerja antar bawahan dan atasan serta lingkungan fisik tempat pegawai bekerja.

\section{KINERJA KARYAWAN}

Kinerja adalah hasil kerja secara kualitas dan kuantitas yang dicapai oleh seorang pegawai dalarn melaksanakan tugasnya sesuai dengan tanggung jawab yang diberikan kepadanya. Kinerja seringkali dipikirkan sebagai pencapaian tugas, dimana istilah tugas sendiri berasal dari pemikiran aktivitas yang dibutuhkan oleh pekerja. Karena kinerja pegawai merupakan suatu tindakan yang dilakukan karyawan dalam melaksanakan pekerjaan yang dilakukan perusahaan.

Kinerja pada dasamya adalah apa yang dilakukan atau tidak dilakukan oleh karyawan. Menurut (Mathis. 2001) kinerja karyawan adalah yang mempengaruhi seberapa banyak mereka memberikan kontribusi kepada organisasi. Kinerja merupakan hal yang sangat penting dalam suatu perusahaan untuk mencapai tujuannya.

\section{HIPOTESIS}

H1 : Diduga terdapat pengaruh positif antara variabel komunikasi organisasi terhadap kinerja karyawan

$\mathrm{H} 2$ : Diduga terdapat pengaruh positif antara variabel lingkungan kerja terhadap kinerja karyawan

\section{METODE PENELITIAN}

Jenis Penelitian 
Jenis penelitian yang digunakan dalam penelitian ini adalah penelitian kuantitatif. Menurut (Sugiyono, 2012) penelitian kuantitatif digunakan untuk meneliti pada populasi atau sampel tertentu. Teknik pengambilan sampel umumnya dilakukan secara random, pengumpulan data mengunakan instrumen penelitian, analisis data bersifat kuantitatif/statistik dengan tujuan untuk menguji hipotesis yang ditetapkan.

\section{Penentuan Sampel}

Dikarenakan jumlah populasi tidak sampai 30 orang maka tidak dilakukan penarikan sampel, sampel pada penelitian ini dilakukan dengan metode sensus/total sampling, dimana populasi dijadikan sampel yaitu sebanyak 26 orang.

\section{Jenis dan Sumber Data}

Jenis data dalam penelitian ini adalah data primer dan sekunder seperti, menyebarkan kuesioner berupa pertanyaan tertulis, dan dokumentasi seperti melihat atau mencatat dokumen-dokumen perusahaan yang berkaitan dengan penelitian.

\section{HASIL PENELITIAN}

\section{Hasil Regresi Berganda}

\section{Coefficients $^{\mathrm{a}}$}

\begin{tabular}{|c|c|c|c|c|c|}
\hline \multirow[b]{2}{*}{ Model } & \multicolumn{2}{|c|}{$\begin{array}{l}\text { Unstandardi } \\
\text { zed } \\
\text { Coefficients }\end{array}$} & \multirow{2}{*}{\begin{tabular}{|c|}
$\begin{array}{c}\text { Standar } \\
\text { dized } \\
\text { Coeffici } \\
\text { ents }\end{array}$ \\
Beta
\end{tabular}} & \multirow[b]{2}{*}{$\mathrm{t}$} & \multirow[b]{2}{*}{ Sig. } \\
\hline & B & $\begin{array}{c}\text { Std. } \\
\text { Error }\end{array}$ & & & \\
\hline 1 (Constant) & $\begin{array}{r}17.7 \\
22\end{array}$ & $\begin{array}{r}11.86 \\
2\end{array}$ & & 1.494 & .149 \\
\hline $\mathrm{x} 1$ & .168 & .221 & .146 & .758 & .456 \\
\hline $\mathrm{x} 2$ & .385 & .206 & .359 & 1.867 & .075 \\
\hline
\end{tabular}

a. Dependent

Variable: Y

\begin{abstract}
Pada tabel korelasi menunjukan suatu hubungan. Korelasi antara hubungan komunikasi organisasi dan lingkungan kerja terhadap kinerja karyawan. Dari tabel diatas dapat diperoleh persamaan regresi linear sebagai berikut :

$\mathrm{Y}=17,722+0,168 \mathrm{X} 1+0,385 \mathrm{X} 2$

Maka dapat disimpulkan bahwa variabel bebas X1 (komunikasi organisasi) dengan kofisien $\quad 0,168$ berpengaruh. Kemudian variabel lain yang berpengaruh adalah X2 (lingkungan kerja) dengan koefisien 0,385 dari persamaan tersebut dilihat bahwa variabel lingkungan kerja berpengaruh positif terhadap kinerja. Sedangkan variabel komunikasi organisasi berpengaruh positif terhadap kinerja dimana persamaan regresi dua predictor $\beta 1$ dan $\beta 2$ bertanda positif, maka dapat diartikan bahwa satu satuan skor kinerja akan dipengaruhi oleh komunikasi organisasi sebesar 0,168 dan lingkungan kerja sebesar 0,385 pada konstanta 17,722.
\end{abstract}

\section{Hasil Uji Simultan (F)}

\begin{tabular}{|c|c|c|c|c|c|}
\hline \multicolumn{6}{|c|}{ ANOVA $^{b}$} \\
\hline Model & $\begin{array}{l}\text { Sum of } \\
\text { Squares }\end{array}$ & $\mathrm{df}$ & $\begin{array}{l}\text { Mean } \\
\text { Square }\end{array}$ & $\mathrm{F}$ & Sig. \\
\hline
\end{tabular}




\begin{tabular}{|c|c|c|c|c|c|}
\hline $\begin{array}{l}\text { Regressi } \\
\text { on }\end{array}$ & 60.173 & 2 & 30.086 & 2.222 & $.131^{\mathrm{a}}$ \\
\hline Residual & 311.366 & 23 & 13.538 & & \\
\hline Total & 371.538 & 25 & & & \\
\hline
\end{tabular}

a. Predictors:

(Constant), $\mathrm{x} 2, \mathrm{x} 1$

b. Dependent

Variable: Y

Berdasarkan hasil pengolahan data dapat dilihat bahwa nilai signifikasi $\mathrm{F}$ hasil pengujian sebesar 0,131 seperti yang dikemukakan pada tabel 4.12. Hal ini berarti signifikasi $F$ lebih besar dari 0,05. Hal ini menunjukkan ada pengaruh yang positif dan signifikan secara simultan/serempak antara komunikasi organisasi, dan lingkungan kerja terhadap kinerja karyawan. Jadi hipotesisnya Ho ditolak Ha diterima.

\section{KESIMPULAN DAN SARAN}

\section{kesimpulan}

Penelitian ini meneliti pengaruh variabel komunikasi organisasi dan lingkungan kerja terhadap kinerja karyawan. Penelitian ini dilakukan dengan menyebarkan kusioner 26 orang responden yang merupakan karyawan Badan Pusat Statistik (BPS) Kabupaten Solok. Data pada penelitian ini diolah menggunakan SPSS 16.00 for windows.

Dari hasil pengujian dengan sofwere SPSS 16.00 for windows disimpulkan bahwa deskripsi dari jawaban para responden terhadap variabel komunikasi organisasi dan lingkungan kerja pada karyawan berdasarkan uji vaiditas dan realibilitas menunjukan bahwa komunikasi organisasi dan lingkungan kerja berpengaruh terhadap kinerja karyawan baik secara instan maupun secara target kerja.
Berdasarkan hasil analisis koefisien regresi berganda antara komunikasi organisasi dan lingkungan kerja berpengaruh positif terhadap kinerja karyawan hal ini meliputi kenyamanan, fasilitas, suasana kerja yang nyaman dan ada hubungan yang baik antara sesama karyawan. Dimana persamaan regresi berganda adalah $\mathrm{Y}=17,722+0,168 \mathrm{X} 1+0,385 \mathrm{X} 2$ selain itu dengan uji $\mathrm{F}$ dilihat bahwa tidak semua faktor komunikasi organisasi dan lingkungan kerja yang memiliki pengaruh signifikan sesuai dengan uji $\mathrm{F}$ tingkat hasil signifikan sebesar 0,131 dengan tingkat uji $\mathrm{F}$ sebesar $0,05(\alpha=5 \%)$.

\section{Saran}

Saran yang bisa disampaikan dalam penelitian ini adalah :

1. Agar Badan Pusat Statistik (BPS) Kabupaten Solok lebih meningkatkan kualitas kinerja karyawan, standar lingkungan kerja, dan komunikasi antar sesama karyawan terjalin lebih erat lagi.

2. Untuk penelitian selanjutnya agar dapat menggunakan dua metode yaitu pembagian kusioner dan wawancara secara langsung.

\section{DAFTAR PUSTAKA}

AA. Anwar Prabu Mangkunegara. (2009). Manajemen Sumber Daya Manusia Perusahaan. Bandung : Rosda.

Agus Gede Yudha Suparta. (2013).

Pengaruh Motivasi Intrinsik,

Komunikasi, dan Kompensasi

Finansial terhadap Kinerja Karyawan pada PT. Maharani Prema Sakti

Denpasar, Jurnal Ekonomi Vo1. Hal 530- 540, UNUD Bali. Frum Ilmiah.

Ardana. (2009). Etika Bisnis dan Profesi. Jakarta: Salemba Empat. 
Arikunto. (2012). Prosedur Penelitian:

Suatu Pendekatan Praktek.Jakarta: Rineka Cipta.

Bachtiar, D. (2012). "Pengaruh Motivasi

Dan Lingkungan Kerja Terhadap

Kinerja Karyawan". "Management

Analysis Journal". Vol. 1 No. 1.

http://journal.unnes.ac.id/sju/index.ph p/maj.

Brent d. Ruben dan Lea P. Stewart. (2013).

Komunikasi dan Perilaku Manusia,

Jakarta: Rajawali.

Ghozali. (2006). Aplikasi Analisis

Multivariate Dengan Program SPSS.

Cetakan Keempat. Semarang: Badan

Penerbit Universitas Diponegoro.

Ghozali. (2013). Aplikasi Analisis

Multivariate dengan Program IBM

SPSS 21 Update PLS Regresi.

Semarang: Badan Penerbit

Universitas Diponegoro. Jurnal

Administrasi Bisnis.

Ghozali, I. (2002). Peran Strategis Manajer Dalam Manajemen Sdm.

Ghozali, I. (2005). Perencanaan Sumber

Daya Manusia (Kunci Keberhasilan

Organisasi). Universitas Negeri

Yogyakarta.

Ghozali, I. (2009). “Aplikasi Analisis

Multivariate dengan Program SPSS “.

Semarang: UNDIP.

Ghozali, I. (2011). “Aplikasi Analisis

Multivariate Dengan Program SPSS".

Semarang: Badan Penerbit

Universitas Diponegoro.

Ghozali Saydam. (2000). Manajemen

Sumber Daya Manusia.Gunung

Agung, Jakarta.

Heizer, Jay. (2001). Prinsip-prinsip

Manajemen Operasi, Penerbit

Selemba Empat, Jakarta. Jurnal

Psikologi Industri Dan Organisasi.
Lubis, A. Y. O., \& Susanti, F. (2019). Pengaruh Gaya Kepemimpinan Dan Kompensasi Terhadap Prestasi Kerja Karyawan (Studi pada PT Japfa Comfeed Indonesia (JCI) Tbk Devisi Fam 1. https://doi.org/10.31227/osf.io/7tbr g

Marlius, D. RD Putra. (2018). Strategi Pengembangan Sulam Bayang. Jurnal Benefita: Ekonomi Pembangunan Manajemen Bisnis Dan Akuntansi. Volume 3. No. 2. Hal. 204-218. http://doi.org/10.22216/jbe.v3i2.34 94

Nardo, R. Evanita, Syahrizal, S. (2018). Pengaruh Kepemimpinan Transformasional, Dan Lingkungan Kerja Non Fisik Terhadap Perilaku Inovatif. JEBI (Jurnal Ekonomi dan Bisnis Islam) 3 (2), 209-215

Nardo, R. Evanita, Syahrizal, S. (2019). The Effect of Transformational Leadership and Non Physical Work Environment on Innovative Behavior with Work Motivation as a Mediation For Employees of Tour And Travel Companies In West Sumatera. 2nd Padang International Conference on Education, Economics, Business and Accounting (PICEEBA-2 2018)

Putra, RY. Marlius, D. (2019). Pengaruh Pendidikan, Pengalaman Kerja dan Etos Kerja Terhadap Kinerja Pegawai Di KPN Batur. Academic Conference For Management 2.

Ridho, M., \& Susanti, F. (2019). Pengaruh Stres Kerja Dan Motivasi Kerja Terhadap Kepuasan Kerja Pada Karyawan Bank Mandiri Syariah Cabang Padang. https://doi.org/10.31227/osf.io/pa2c $\mathrm{g}$

Susriyanti, S. Nardo, R. (2019). Pengaruh Fungsi Komunikasi Dan Kepuasan Kerja Karyawan Terhadap 
Pemberian Pelayanan Nasabah PT. BPR LPN Talawi Sakato. Jurnal Administrasi Sosial dan Humaniora 3 (2), 97-111.

Yudistira, D. S., \& Susanti, F. (2019). Pengaruh Motivasi Kerja Dan Budaya Kerja Terhadap Kinerja Karyawan Dinas Pemberdayaan Masyarakat Dan Desa, Pengendalian Penduduk Dan Keluarga Berencana Kabupaten Pesisir Selatan. https://doi.org/10.31227/osf.io/jk54 $\mathrm{m}$ 